\title{
Performance Analysis of Transient Current Limiters in a Distribution System
}

\author{
Alok Kumar Shrivastav \\ Electrical Engineering Dpt \\ Techno India Batanagar \\ Kolkata, India \\ alok5497@gmail.com
}

\author{
Pradip Kumar Sadhu \\ Electrical Engineering Dpt \\ Indian Institute of Technology (ISM) Dhanbad \\ Jharkhand, India \\ pradip_sadhu@yahoo.co.in
}

\author{
Ankur Ganguly \\ Electrical Engineering Dpt \\ Techno India Batanagar \\ Kolkata, India \\ anksjc2002@yahoo.com
}

\begin{abstract}
In this study, a simple, but effective method is presented for the limitation of the Y-yg transformers transient current. One of the main privileges of this method is its simple topology. It does not need any control circuit or measurement unit. The method is based on a three-phase thyristor bridge with a low resistance reactor. Since the number of thyristors is minimized, the voltage ripple, electrical losses and the malfunction probability owing to device failure are decreased considerably. The proposed method is simulated and validated by MATLAB simulation and conventional methods test results. It is shown that the proposed configuration is effective for the transient current limitation of $\mathrm{Y}$-yg transformers
\end{abstract}

Keywords- transient current limiter; TCL; stability analysis; fast Fourier transform; FFT; harmonic restraint, error analysis

\section{INTRODUCTION}

Nowadays power systems have been commonly operated with the maximum possible capacity and closer to their stability boundaries due to various reasons such as rapid increase in electricity demand and deregulation of electricity markets. This decreases the power system marginal security in case of instabilities. Under such circumstances, when a circuit breaker is charged, a high transient current flows for a little time until normal flux conditions are established. During most practical system conditions, this transient current's value is high. This transient current, rich in all harmonics, has been found to cause wide raging disturbances in power system and power supplies [1]. In recent years, some solutions have been recommended to overcome the problem with diode bridge-DC reactors and voltage source PWM converters. In addition, a control strategy has been proposed for the assessment of SAPFs (shunt active power filters), based on the Lyapunov control theory, defines a stable operating region for the interfaced converter during the integration time with the utility grid [2]. Authors in [3] developed a wye-delta multi-function balance transformer based power quality control systems (MBT-PQCS). In [5], authors formulated the indirect matrix converter (IMC)-based unified power quality conditioner topology for a photovoltaic (PV) system for solving the power quality functionalities. In [6], an exhaustive simulation model based on mathematical model of a three-phase, shunt active power filter has been developed. In [9], the performance of the transformer magnetic flux under phase-hop condition is investigated and compared with different operating conditions using finite elements. These methods have some drawbacks like voltage drop, while they need bypass resistance, additional control circuits and switching devices. In [10], two different types of measurement equipment are presented comparatively for power quality assessment. In [12], shunt compensation based power quality enhancement is shown. However, the controller stability is not discussed in any of the available research methods.

This paper's objective is to investigate stable and harmonic free, transient current limiters (TCLs). In this context, two different types of TCLs based three-phase converter were proposed, twelve pulse and six-pulse. The first stage had presented the mathematical and simulation considerations of transients that occur during closing of circuit breaker and energizing of transformer and the second stage address the comparative loom of stability and the total harmonic distortion (THD) between twelve-pulse and six-pulse converter based three-phase thyristor bridge system.

\section{SERIES TCL FOR THREE-PHASE Y-YG TRANSFORMER}

Transient current in circuit breaker results from any abrupt change in the magnetizing voltage. The transient current waveform consists of a large and long lasting $\mathrm{AC}$ component and harmonics [16]. The TCL, has a low resistance coil in order to gain better results. The series TCL connected to threephase breaker and primary side of three single-phase transformers operates in two modes, charging mode and discharging mode [16]. The present mathematical statement in charging mode is composed, as takes after [16].

$$
\begin{aligned}
& i(t)=e^{-(R / L) t}\left(\frac{-V p}{\sqrt{\left(R^{2}\right)+\left(w L^{2)}\right.}} \sin \left(w t_{1}-\delta\right)+\frac{2 V_{T F}}{R}\right)+ \\
& \frac{V p}{\sqrt{\left(R^{2}\right)+\left(w L^{2}\right)}} \sin \left(w t_{2}-\delta\right)-\frac{V_{T F}}{R}
\end{aligned}
$$

where $R=R_{P}+R_{T C L}\left(R_{p}\right.$ is the resistance in the primary side of the transformer and $R_{T C L}$ is the reactor resistance), $L=L_{p}+L_{T C L}+L_{m}$ ( $L_{p}$ is the leakage spillage inductance in the essential side of the transformer and $L_{T C L}$ is the reactor 
inductance and $L_{m}$ is the charging inductance of the transformer), $V_{T F}$ is the forward thyristor voltage drop and $V_{p}$ is the crest plentifulness of the utility voltage.

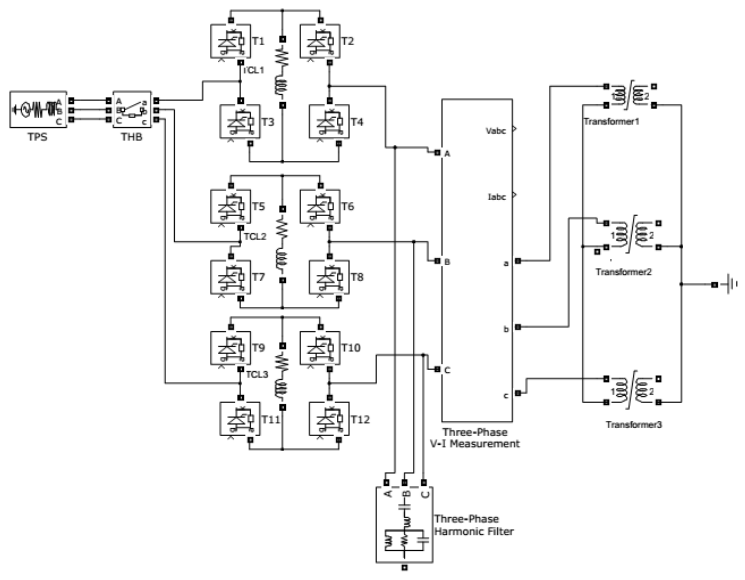

Fig. 1. Three single phase TCL connected in series with Y-yg transformer

\section{PPOPOSED TCL}

As shown in [16] the transient current of the three-stage transformer can be controlled by utilizing twelve thyristors of the arrangement TCL. Through these thyristors, considerable current of the loaded transformers flows. Therefore, they are costly as well as unstable. Hence, to make the system stable and harmonics free, a modified circuit is proposed which is shown in Figure 2 [16]

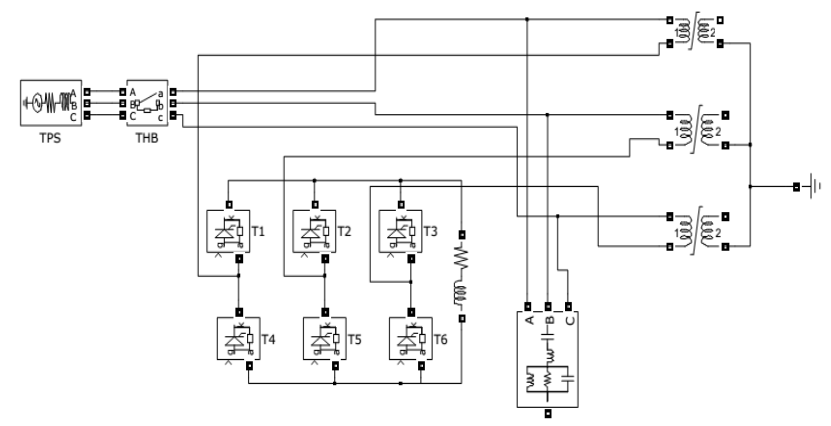

Fig. 2. Proposed TCL connected to Y-yg transformer

\section{Charging MODE}

According to Figure 3, the coil in comparison by neglecting $\mathrm{R}_{1}$ and $\mathrm{L}_{1}$ is communicated as, charging method of conducting coil [7] and can be written as follows:

$$
V_{L L} \sin (w t-30)=2 R_{p} i_{1}+2 L_{p} \frac{d i_{1}}{d t}+
$$$$
2 V_{T F}+L_{T C L} \frac{d i_{1}}{d t}+R_{T C L} i_{1}+2 \frac{d \varphi}{d t}
$$

$$
\begin{aligned}
& w V_{L L} \sin (w t-30)=2 R_{p} i_{1}+2 L_{p} \frac{d i_{1}}{d t}+ \\
& L_{T C L} \frac{d^{2} i_{1}}{d t^{2}}+R_{T C L} \frac{d i_{1}}{d t}+2 \frac{d^{2} \varphi}{d t^{2}}
\end{aligned}
$$

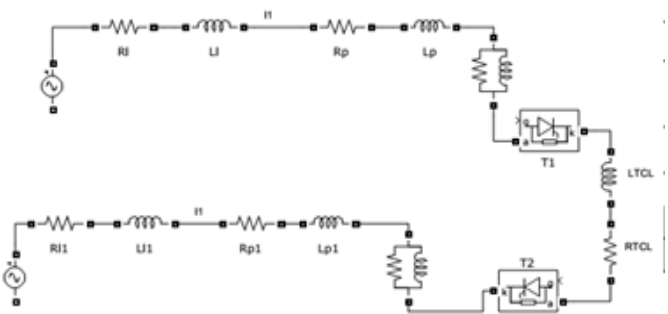

Fig. 3. Coil charging mode

It is clear that

$$
i_{1}(t)=i_{m}(t)+i_{c}(t)
$$

$$
\frac{d \phi}{d t}=R_{c} i_{c}
$$

and

$$
\frac{d \varphi}{d t}=\frac{d \varphi}{d i_{m}} * \frac{d i_{m}}{d t}=L_{m} \frac{d i_{m}}{d t}
$$

Utilizing (4), (5) and (6) the accompanying comparison can be represented as

$$
\begin{aligned}
& i(t)=i_{m 1} e^{F t}+i_{m 2} e^{G t}+i_{m 3} \sin (w t+\varphi)+i_{m 4} \\
& \frac{d^{2} \phi}{d t^{2}}=R_{c} \frac{d i_{1}}{d t}-\frac{R_{c}}{L_{m}} \frac{d \phi}{d t}
\end{aligned}
$$

Supplanting (7) in (3), we get (8)

$$
\begin{aligned}
& w V_{L L} \cos (w t-30)=2 R_{p} \frac{d i_{1}}{d t}+2 L_{p} \frac{d^{2} i_{1}}{d t^{2}}+L_{T C L} \frac{d^{2} i_{1}}{d t^{2}}+ \\
& R_{T C L} \frac{d i_{1}}{d t}+2\left(R_{c} \frac{d i_{1}}{d t}-\frac{R_{c}}{L_{m}} \frac{d \varphi}{d t}\right)
\end{aligned}
$$

Comparing (2) with (8) can be revised in the accompanying structure

$$
A \frac{d^{2} i_{1}}{d t^{2}}+B \frac{d i_{1}}{d t}+C i_{1}=D \sin (w t+\alpha)+E
$$

where

$$
\begin{aligned}
& A=L_{m} \frac{2 L_{p}+L_{T C L}}{R_{C}} \\
& B=L_{m}\left(\frac{2 R_{p}+R_{T C L}}{R_{c}}\right)+2 L_{p}+L_{T C L}+2 L_{m} \\
& C=2 R_{p}+R_{T C L} \\
& D=V_{L L} \sqrt{\frac{R_{c}^{2}+L_{m}^{2} w^{2}}{\left(R_{c}\right)^{2}}}
\end{aligned}
$$

Differentiating (2) leads to the following equation: 


$$
\begin{aligned}
& E=-2 V_{T F} \\
& \alpha=\varphi-30 \\
& \cos \varphi=\frac{V_{L L}}{D}
\end{aligned}
$$

Using Laplace transform, (9) can be rewritten, as follows

$$
\begin{aligned}
& A\left(s^{2} I(s)-s I(0)-I^{\prime}(0)\right)+B(s I(s)-I(0))+C I(s)= \\
& D \frac{s \sin (\alpha)+w \cos (\alpha)}{s^{2}+w^{2}}+\frac{E}{S}
\end{aligned}
$$

Consequently

$$
\begin{aligned}
& I(s)=D \frac{s \sin (\alpha)}{\left(s^{2}+\omega^{2}\right)\left(A s^{2}+B s+C\right)}+D \frac{\omega \cos (\alpha)}{\left(s^{2}+\omega^{2}\right)\left(A s^{2}+B s+C\right)}+ \\
& \frac{E}{s\left(A s^{2}+B s+C\right)}
\end{aligned}
$$

Utilizing the inverse Laplace transform, the transient current somewhere around 0 and $\mathrm{T} / 4$ can be dictated by the accompanying equation.

$$
i(t)=i_{m 1} e^{F t}+i_{m 2} e^{G t}+i_{m 3} \sin (w t+\varphi)+i_{m 4}
$$

where

$$
\begin{aligned}
& i_{m 1}=\left(\frac{E}{F(F-G)}+\frac{D F \sin (\alpha)}{(F-G)\left(F^{2}+w^{2}\right)}+\frac{D w \cos (\alpha)}{(F-G)\left(F^{2}+w^{2}\right.}\right) \\
& i_{m 2}=\left(\frac{E}{G(G-F)}+\frac{D G \sin (\alpha)}{(G-F)\left(G^{2}+w^{2}\right)}+\frac{D w \cos (\alpha)}{(G-F)\left(G^{2}+w^{2}\right)}\right) \\
& i_{m 3}=\left(\frac{2 w D}{\sqrt{4 w^{4}(F+G)^{2}\left(2 w F G-2 w^{3}\right)^{2}}}\right) \\
& i_{m 4}=\frac{E}{G F} \\
& F=\frac{-B+\sqrt{B^{2}-4 A C}}{2 A} \\
& G=\frac{-B-\sqrt{B^{2}-4 A C}}{2 A}
\end{aligned}
$$$$
\cos (\gamma)=\frac{\left(2 w F G-2 w^{3}\right) \cos (\alpha)-\left(2 w^{2}(F+G)\right) \sin (\alpha)}{\sqrt{4 w^{4}(F+G)^{2}+\left(2 w F G-2 w^{3}\right)^{2}}}
$$

As given in (12), the charging mode somewhere around 0 and $\mathrm{T} / 4$ comprises of two exponential and one sinusoidal segment. Since $F$ and $G$ are negative, these two exponential parts will tend to decay.

\section{STABILITY ANALYSIS}

The performance and stability analysis of the process under investigation are carried out using the simulated model that is formulated based on the physical properties of the real process. Figures 4 to 8 , illustrate the impact of TCL on voltage stability of grid-connected photovoltaic system by conventional linear stability analysis tools like Bode, Nyquist and Nichols Chart.

\section{A. Bode Plot Analysis}

This method is very helpful for determining the stability of a system. It is a logarithmic plot, so they collapse a wide range of frequencies on the horizontal axis and a wide range of gains on the vertical axis into a completely viewable plot. From (11)
Bode analysis is done to check the stability of the system shown in Figures 1-2. Result shows that the preceding system is unstable but the modified system shown in the Figure 2 is stable considering the same gain margin and other parameters are also constant.

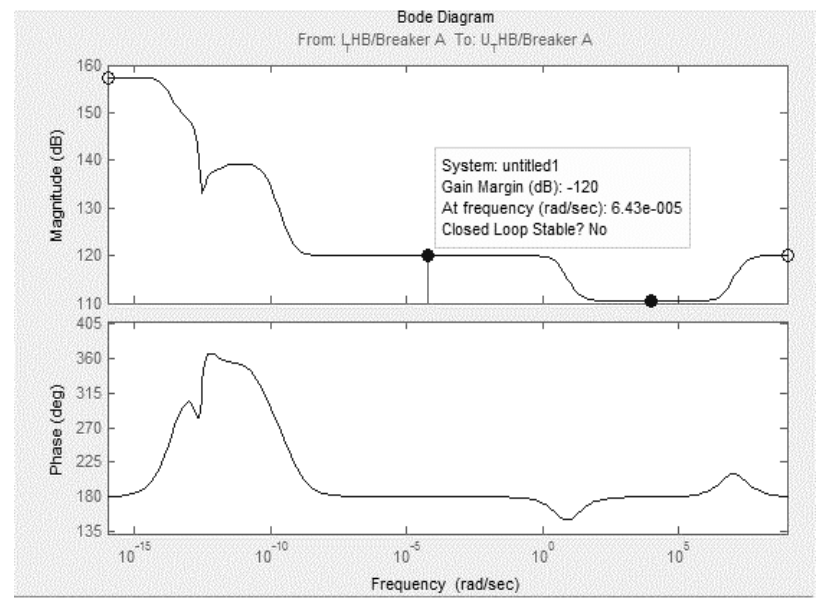

Fig. 4. Bode diagram for line current stability of Figure 1

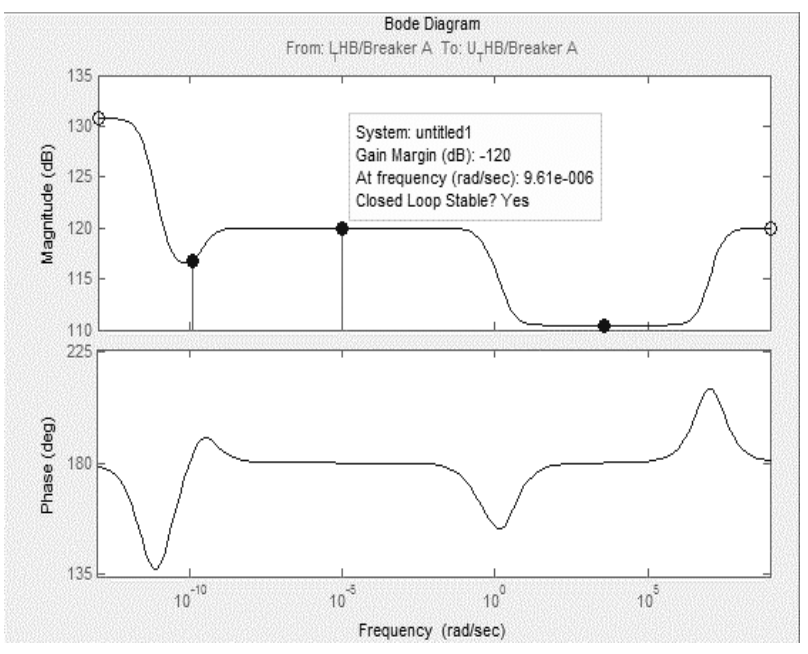

Fig. 5. Bode diagram for line current stability of Figure 2

\section{B. Nyquist Plot Analysis}

This is a parametric plot of a frequency response obtained from (11), used for assessing the stability of the system shown in Figures 1-2. In, Nyquist plot, if TGH contour does not encircle the critical point and the open loop system doesn't possess any open loop pole at the right half of s-plane then the system is stable. Figures 6-7 illustrate the stability of the model presented in Figures 1-2.

\section{Nichols Plot Analysis}

In this method, derived from (11), considering constantmagnitude loci and constant phase-angle loci in the logmagnitude versus phase diagram. The magnitude in $\mathrm{dB}$ monotonically decreases with increase in frequency. A 
comparative stability analysis of Figure 1-2 is shown, which implicates the results shown in figure 8 is unstable and figure 9 is stable considering the same value of gain margin.

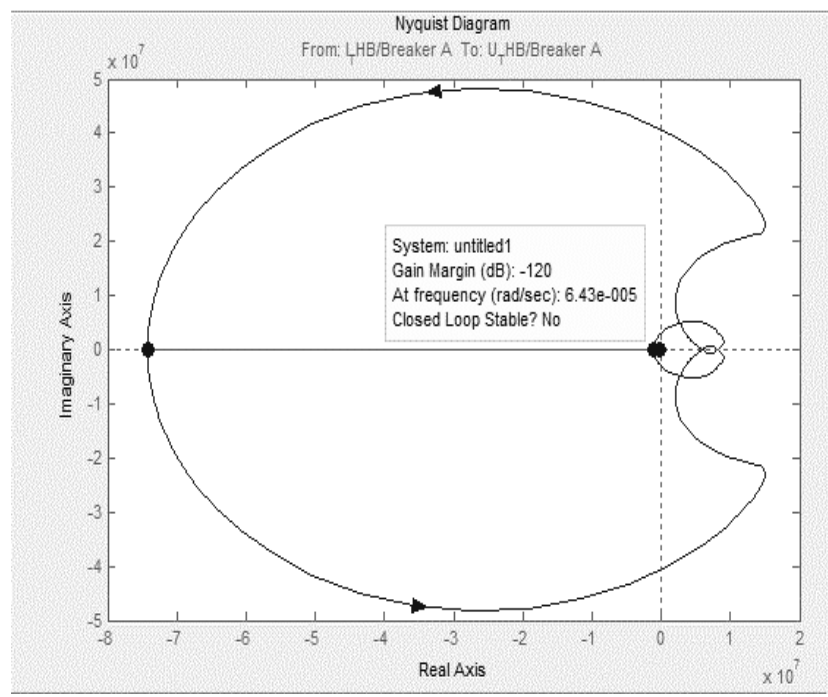

Fig. 6. Nyquist diagram for line current stability of Figure 1

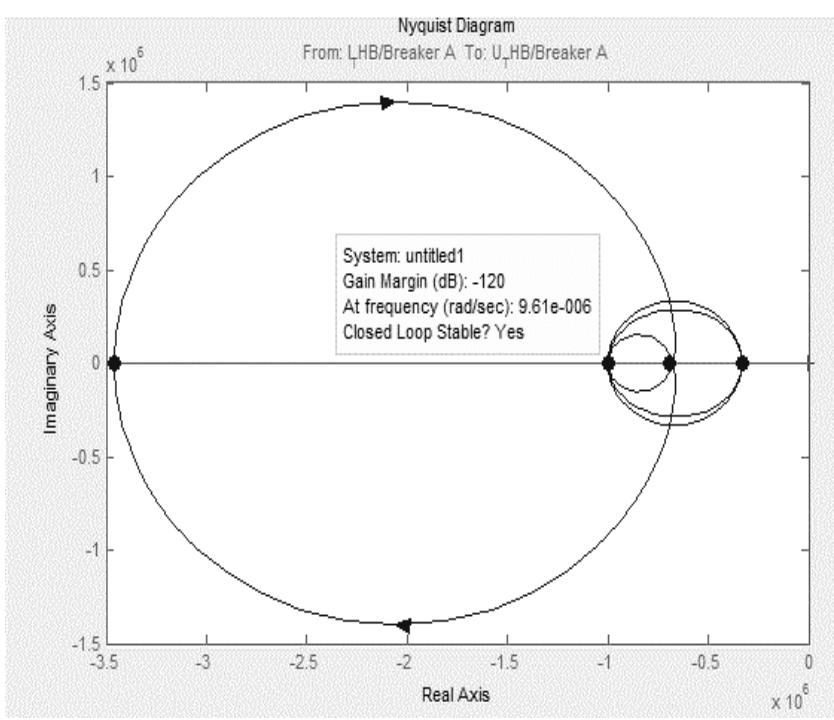

Fig. 7. Nyquist diagram for line current stability of Figure 2

\section{TOTAL HARMONIC DISTORTION ANALYSIS}

In this paper, fast Fourier transform (FFT) method has been applied for harmonic assessment in single-phase signals of Figure 1 and Figure 2. By this fundamental technique, the amplitude and phase angle of harmonic components can be individually determined. The results show that the proposed TCL circuit shown in Figure 2 is more efficient than the system shown in Figure 1. Figures 10-11 show the FFT output and THD analysis for 50 and $60 \mathrm{~Hz}$ for TCL systems in Figures 1 and 2 respectively.

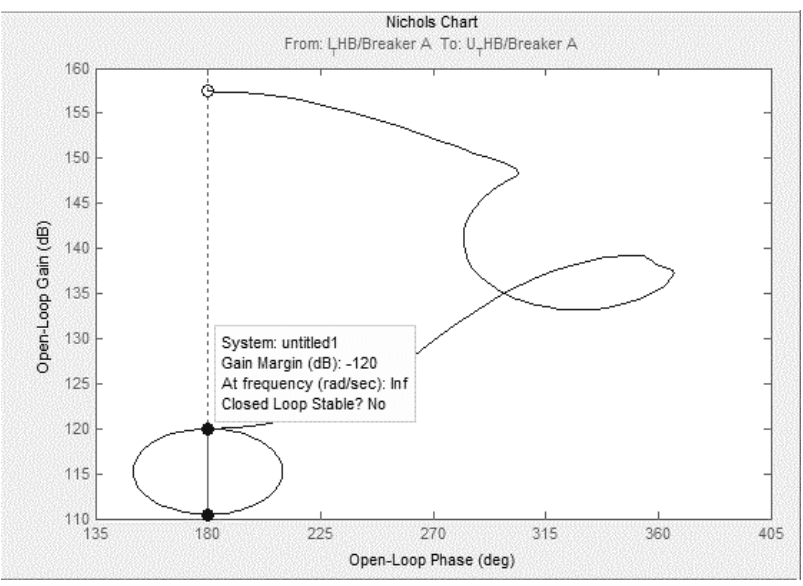

Fig. 8. Nichols diagram for line current stability of Figure 1

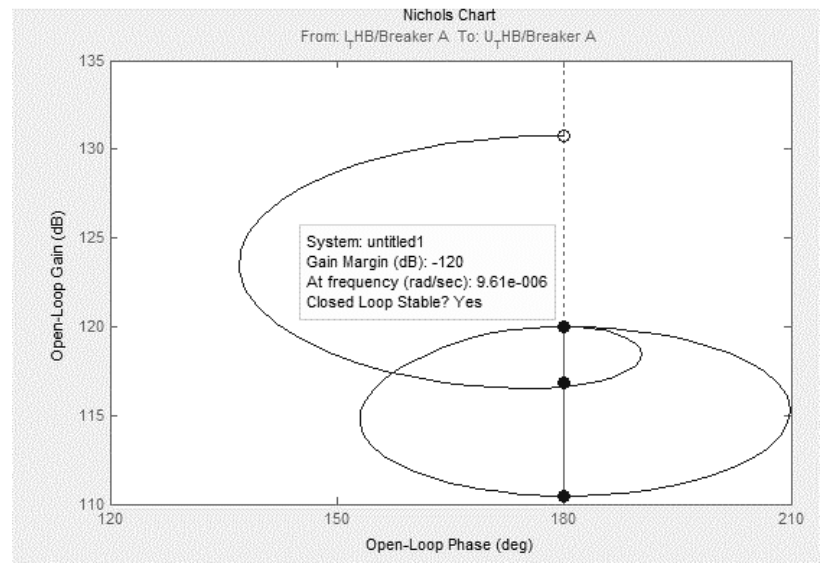

Fig. 9. Nichols diagram for line current stability of Figure 2

\section{RESULTS AND DISCUSSION}

The simulations are carried out in Matlab. The comparative analysis and simulation parameters are given in Tables II-III. Figures 4-5, Figures 6-7 and Figures 8-9 show the close loop stability of the system shown in Figure 1 and Figure 2 using conventional methods such as Bode, Nyquist and Nichols. As shown in Figures 4, 6 and 8, the close loop system becomes unstable without using modified TCL or it can be stable using the conventional TCL as shown in Figures 5, 7 and 9. Figure 10 (a)-(c) shows the harmonic distortion of Figure 1 at different frequency. Figure 11 (a)-(c) illustrates the harmonic analysis for the transformer current using conventional TCL shown in Figure 2. A comparison of these figures shows that using the proposed TCL results in the reduction of the THD amplitude. The system harmonic parameters up to sixteenth order with and without using the proposed TCL are listed in Table I. This test verifies the effectiveness of the proposed TCL for limiting the unwanted harmonics. The results show that the transient current has been limited significantly, which will downsize the nominal values of all circuit elements owing to the new current scale. Evidently, this is gained in the cost of adding the TCL. 


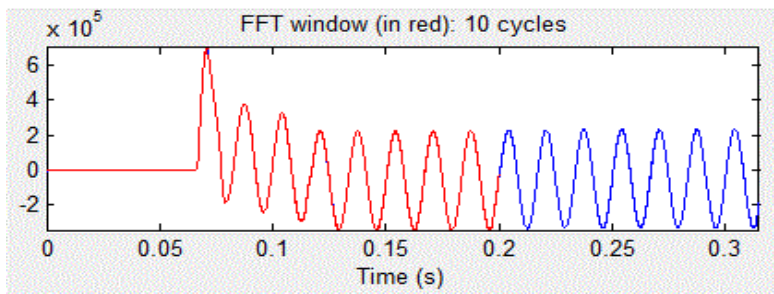

(a)

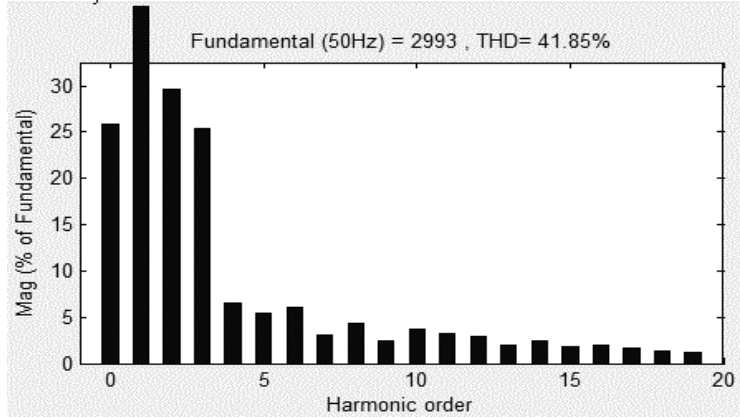

(b)

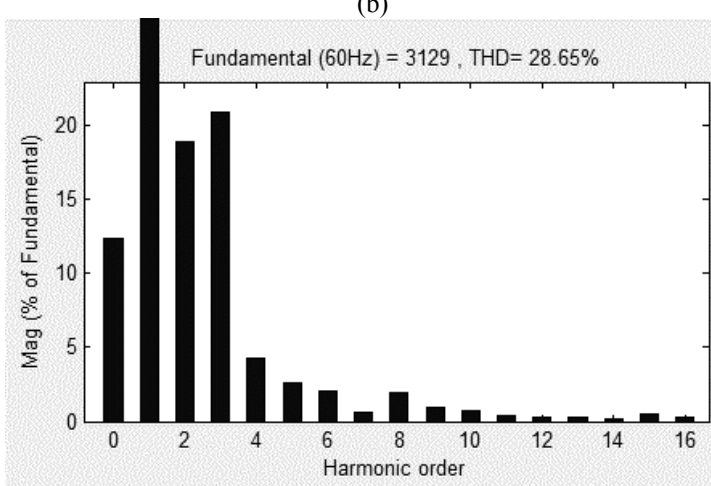

(c)

Fig. 10. (a) FFT output, (b) THD analysis at 50Hz, (c) THD analysis at $60 \mathrm{~Hz}$ for TCL system shown in Figure 1

TABLE I. COMPARATIVE PARAMETER ANALYSIS

\begin{tabular}{|c|c|c|}
\hline Parameters & Figure2 & Figure3 \\
\hline Sampling time & $5.49369 \mathrm{e}-007 \mathrm{~s}$ & $6.56117 \mathrm{e}-007 \mathrm{~s}$ \\
\hline Samples per cycle & 30337.8 & 25402 \\
\hline $\begin{array}{c}\text { Total Harmonic } \\
\text { Distortion (THD) }\end{array}$ & $28.65 \%$ & $0.19 \%$ \\
\hline $\begin{array}{c}\text { Max } \\
\text { for frequency used } \\
\text { for THD calculation }\end{array}$ & $910020.00 \mathrm{~Hz}$ & $761940.00 \mathrm{~Hz}$ \\
\hline
\end{tabular}

TABLE II. SIMULATION PARAMETERS

\begin{tabular}{|c|c|c|c|}
\hline Parameters & Value & Parameter & Value \\
\hline$R_{p}$ & $0.65 \Omega$ & LTCL & $0.8 \mathrm{H}$ \\
\hline$R_{1}$ & $0.05 \Omega$ & RTCL & $0.03 \Omega$ \\
\hline$L_{p}$ & $0.0025 \mathrm{H}$ & VTF & $10 \mathrm{~V}$ \\
\hline$L_{1}$ & $0.001 \mathrm{H}$ & $\omega$ & 314.15 \\
\hline$L_{m}$ & $0.9 \mathrm{H}$ & $\mathrm{S}$ & $20 \mathrm{MVA}$ \\
\hline$R_{c}$ & $2000 \Omega$ & $\mathrm{VLL}$ & $2000\left(\mathrm{~V}_{\mathrm{rms}}\right)$ \\
\hline
\end{tabular}

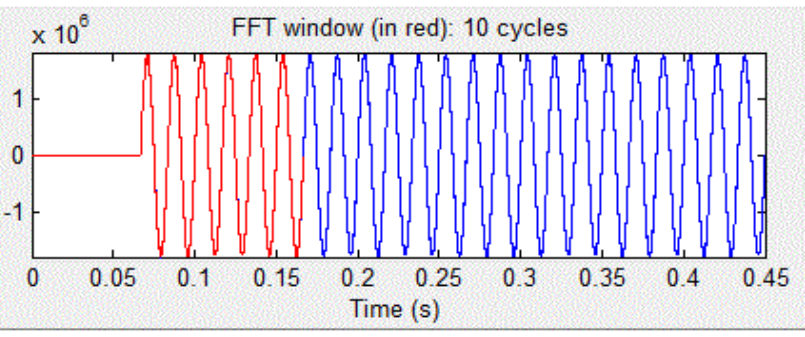

(a)

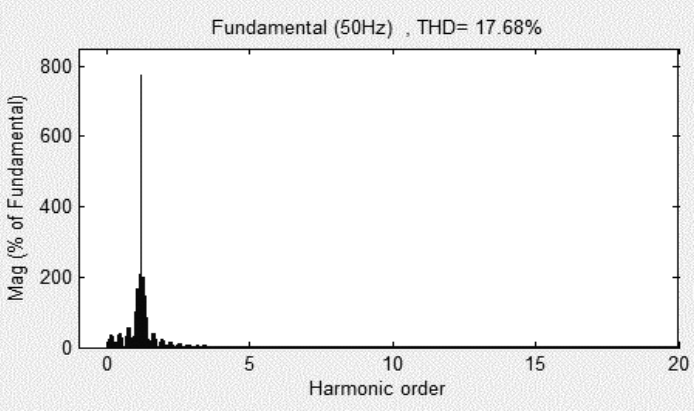

(b)

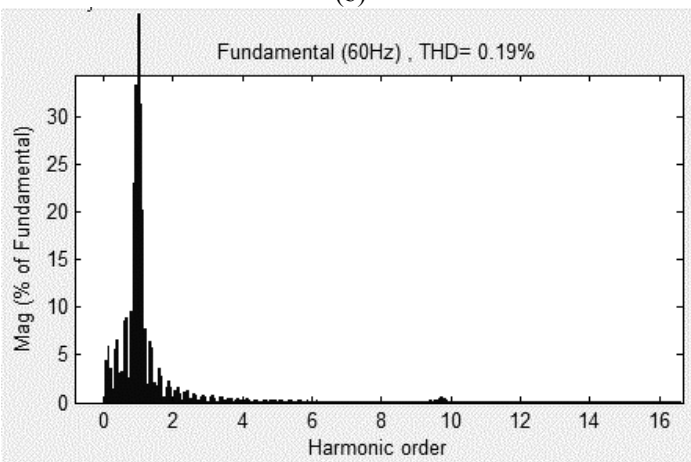

(c)

Fig. 11. (a) FFT output, (b) THD analysis at 50Hz, (c) THD analysis at $60 \mathrm{~Hz}$ for TCL system shown in Figure 2

TABLE III. COMPARISON OF SYSTEM STABILITY AND HARMONIC ANALYSIS WITH AVAILABLE TECHNIQUES

\begin{tabular}{|c|c|c|}
\hline System Analysis & Stability Analysis & THD Analysis \\
\hline Proposed Method & System Stable & $0.19 \%$ \\
\hline$[4]$ & N.A & $4.05 \%$ \\
\hline$[5]$ & N.A & $4.3 \%$ \\
\hline$[2]$ & N.A & $16.5 \%$ \\
\hline$[3]$ & N.A & $22.3 \%$ \\
\hline$[6]$ & N.A & $30.8 \%$ \\
\hline \multicolumn{2}{|c}{}
\end{tabular}

\section{CONCLUSIONS}

In this paper, a comparative study between two efficient TCLs, based on a three-phase thyristor bridge system for the mitigation of transient occurs during the closing of circuit breaker and charging of transformer has been proposed. The main advantage of the proposed limiter is that it can automatically provide high impedance to restrain the transient current phenomenon and it will not cause distortion in the steady-state load voltage or current waveforms. The proposed TCL has a simple topology, does not need any controlling 
circuit and uses fewer thyristors than other TCLs. In addition, it gives a stable output, lower voltage drop, ripple, and lower harmonic distortion for transformers. The simulation results show the effectiveness of the proposed TCL. Moreover, this technique is shown to be effective in stability analysis of power systems in distribution area.

\section{REFERENCES}

[1] M. Tarafdar Hagh, M. Abapour, "DC Reactor Type Transformer Inrush Current Limiter”, IET Electric Power Applications, Vol.1 No. 5, pp. 808-814, 2007

[2] M. Mehrasa, E. Pouresmaeil, S. Zabihi, E. M. G. Rodrigues, J. P. S Catalao, "A control strategy for the stable operation of shunt active power filters in power grids", Energy, Vol. 96, pp. 325-334, 2016

[3] S. Hu, Z. Zhang, B. Xie, M. Chen, A. Kubis, "A wye-delta multifunction balance transformer based power quality control system for single-phase power supply system", IEEE Conference on Electrical Systems for Aircraft, Railway, Ship Propulsion and Road Vehicles, Aachen, Germany, pp. 110-116, March 3-5, 2015

[4] W. Frangieh, M. B. Najjar, "Active control for power quality improvement in hybrid power systems", Third International Conference on Technological Advances in Electrical, Electronics and Computer Engineering, Beirut, Lebanon, pp. 218-223, April 29- May 1, 2015

[5] T. Geury, S. Pinto, J. Gyselinck, P. Wheeler, "An indirect matrix converter-based unified power quality conditioner for a PV inverter with enhanced power quality functionality", IEEE Innovative Smart Grid Technologies - Asia, Bangkok, Thailand, pp. 1-8, November 3-6, 2015

[6] A. Farooq, A. H. Bhat, "Performance evaluation of a three phase shunt active power filter for power quality improvement", International Conference on Recent Developments in Control, Automation and Power Engineering, Noida, India, pp. 214-219, March 12-13, 2015

[7] D. I. Taylor, J. D. Law, B. K. Johnson, N. Fischer, "Single-phase transformer inrush current reduction using prefluxing", IEEE Transactions on Power Delivery, Vol. 27, No. 1, pp. 245-252, 2012

[8] A. Farazmand, F. de Leon, K. Zhang, S. Jazebi. "Analysis, Modeling and Simulating of the Phase-Hop Condition in Transformers: The Largest Inrush Currents", IEEE Transactions On Power Delivery, Vol. 29, No. 4, pp. 168-174, 2014

[9] A.-M. Dumitrescu, R. Roman, M. Albu, "Synchronized measurements and power quality assesment", IEEE Eindhoven Power Tech, Eindhoven, Netherlands, pp. 1-6, June 29-July 2, 2015

[10] B. E. Kushare, A. A. Ghatol, T. N. Date, "Power quality survey of 33KV indian industrial supply system: Results and remedial actions", International Power Engineering Conference, Singapore, pp. 320-325, December 3-6, 2007

[11] T. D. C. Busarello, M. Godoy Simoes, "Power quality enhancement by means of shunt compensators based on the conservative power theory", Clemson University Power Systems Conference, Clemson, USA, March 10-13, 2015

[12] M. I. Shaik, M. M. Hussain, M. S. Habeeb, S. Suraya, "Neutral point clamped based active power filter for power quality improvement", International Conference on Electrical, Electronics, Signals, Communication and Optimization, Visakhapatnam, India, January 2425,2015

[13] J. H. Brunke, K. J. Frohlich, "Elimination of transformer inrush currents by controlled switching - part I: theoretical considerations", IEEE Transactions on Power Delivery, Vol, 16, No.2, pp. 276-280, 2001

[14] T. Hoshino, K. M. Salim, A. Kawasaki, I. Muta, T. Nakamura, M. Yamada, "Design of $6.6 \mathrm{kV}, 100$ A saturated DC reactor type superconducting fault current limiter", IEEE Transactions on Applied Superconductivity, Vol, 13, No.2, pp. 2012-2015, 2003

[15] K. L. Lian, B. K. Perkins, P. W. Lehn, "Harmonic analysis of a threephase diode bridge rectifier based on sampled-data model", IEEE Transactions on Power Delivery, Vol. 23, No. 2, pp. 1088-1096, 2008

[16] A. Kumar Shrivastav, P. Kumar Sadhu, A. Ganguly, N. Pal, "A Novel Transient Fault Current limiter based on three phase Thyristor Bridge for
Y-yg transformer" International Journal of Power Electronics and Drive Systems, Vol. 6, No. 4, pp.747-758, 2015

[17] X. N. Lin, P. Liu, "The ultra-saturation phenomenon of loaded transformer energisation and its impacts on differential protection", IEEE Transactions on Power Delivery, Vol. 20, No. 2, pp. 1265-1272, 2005

[18] A. K. Al-Khalifah, E. F. Al-Saadany, "Investigation of magnetizing inrush current in a single-phase transformer", IEEE Large Engineering Systems Conference on Power Engineering, Halifax, Canada, pp. 165171, July 26-28, 2006

[19] Y. Cui, S. Abdulsalam, S. Chen, W. Xu, "A sequential phase energization technique for transformer inrush current reduction - part I: simulation and experimental results", IEEE Power Engineering Society General Meeting, Denver, USA, Vol. 1, pp. 535, June 6-10, 2004 